\title{
Correction to: Genetic Diversity Among Genogroup II Noroviruses and Progressive Emergence of GII.17 in Wastewaters in Italy (2011-2016) Revealed by Next-Generation and Sanger Sequencing
}

\author{
E. Suffredini ${ }^{1} \cdot$ M. laconelli ${ }^{2} \cdot$ M. Equestre ${ }^{3} \cdot$ B. Valdazo-González ${ }^{4} \cdot$ A. R. Ciccaglione ${ }^{5} \cdot$ C. Marcantonio $^{5}$. \\ S. Della Libera ${ }^{2} \cdot$ F. Bignami $^{2} \cdot$ G. La Rosa ${ }^{2}$ (D)
}

Published online: 4 May 2018

(c) Springer Science+Business Media, LLC, part of Springer Nature 2018

\section{Correction to: Food and Environmental Virology https://doi.org/10.1007/s12560-017-9328-y}

The original version of this article unfortunately contained a mistake. The presentation of Table 1 was incorrect. The corrected table is given below. The original article has been corrected.

The original article can be found online at https://doi.org/10.1007/ s12560-017-9328-y.

G. La Rosa

giuseppina.larosa@iss.it

1 Department of Food Safety, Nutrition and Veterinary Public Health, Istituto Superiore di Sanità, Rome, Italy

2 Department of Environment and Health, Istituto Superiore di Sanità, Rome, Italy

3 Department of Cell Biology and Neurosciences, Istituto Superiore di Sanità, Rome, Italy

4 The National Institute for Biological Standards and Control, The Medicines and Healthcare Products Regulatory Agency, Blanche Lane, South Mimms, Potters Bar, Herts EN6 3QG, UK

5 Department of Infectious Diseases, Istituto Superiore di Sanità, Rome, Italy 
Table 1 Primers used in the present study

\begin{tabular}{|c|c|c|c|c|c|}
\hline Region & Primer name & Primer $\left(5^{\prime}-3^{\prime}\right)$ & $\begin{array}{l}\text { Length } \\
\text { (bp) }\end{array}$ & Cycle & References \\
\hline \multicolumn{6}{|c|}{ Real-time RT-(q)PCR for GII NoV } \\
\hline $\begin{array}{l}\text { ORF1-ORF2 } \\
\text { junction }\end{array}$ & $\begin{array}{l}\text { QNIF2 } \\
\text { COG2R } \\
\text { QNIFs }\end{array}$ & $\begin{array}{l}\text { ATGTTCAGRTGGATGAGRTTCTCWGA } \\
\text { TCGACGCCATCTTCATTCACA } \\
\text { FAM-AGCACGTGGGAGGGCGATCG-TAMRA }\end{array}$ & - & $\begin{array}{l}\text { One-step real- } \\
\text { time }\end{array}$ & $\begin{array}{l}\text { Kageyama et al. (2003), } \\
\text { Loisy et al. (2005) }\end{array}$ \\
\hline \multicolumn{6}{|c|}{ Broad-range GII NoV nested RT-PCR } \\
\hline ORF2 & $\begin{array}{l}\text { COG2F } \\
\text { G2SKR } \\
\text { G2SKF } \\
\text { G2SKR }\end{array}$ & $\begin{array}{l}\text { CARGARBCNATGTTYAGRTGGATGAG } \\
\text { CCRCCNGCATRHCCRTTRTACAT } \\
\text { CNTGGGAGGGCGATCGCAA } \\
\text { CCRCCNGCATRHCCRTTRTACAT }\end{array}$ & 344 & 2nd round & $\begin{array}{c}\text { Kageyama et al. (2003), } \\
\text { Kojima et al. (2002) }\end{array}$ \\
\hline \multicolumn{6}{|c|}{ Specific GII.17 NoV nested RT-PCR } \\
\hline ORF2 & $\begin{array}{l}2063 \\
2062 \\
2104 \\
2064\end{array}$ & $\begin{array}{l}\text { GCTCCATCTAATGATGGTG } \\
\text { TCCACTGGGAAATTTGGC } \\
\text { TGGTCTCGTACCAGAGGG } \\
\text { GATCTTTCCGGCAGTGAAC }\end{array}$ & 368 & 2nd round & La Rosa et al. (2017) \\
\hline \multicolumn{6}{|c|}{ GII.17 ORF1-ORF2 junction nested RT-PCR } \\
\hline $\begin{array}{l}\text { ORF1-ORF2 } \\
\text { junction }\end{array}$ & $\begin{array}{l}\text { GIIPF800 M } \\
\text { GIICR1450 } \\
\text { GIIPF750 M } \\
\text { GII-R1 M }\end{array}$ & $\begin{array}{l}\text { GATGCWGAYTAYTCYMGNTGGGA } \\
\text { ACCCARGMNTCAAAYCTRAART } \\
\text { CNGCHHTAGARRTNATGGT } \\
\text { CCRCCNGCATRNCCRTTRTACAT }\end{array}$ & 2354 & $\begin{array}{l}\text { 1st cycle } \\
\text { 2nd round }\end{array}$ & Koo et al. (2017) \\
\hline
\end{tabular}

Real-time probe labeled at the 5'-end with 6-carboxyfluorescein (FAM) and at the 3'-end with 6-carboxytetramethylrhodamine (TAMRA) 